\title{
Estimation of 10 - year probability bone fracture in a selected sample of Palestinian people using fracture risk assessment tool
}

\author{
Mai B Aker ${ }^{1}$, Adham S Abu Taha², Sa'ed H Zyoud², Ansam F Sawalha², Samah W Al-Jabi and Waleed M Sweileh²
}

\begin{abstract}
Background: The Fracture Risk Assessment (FRAX) tool has been developed by the World Health Organization $(\mathrm{WHO})$ to calculate 10-year probability hip fracture (HP) or major osteoporotic fracture (MOF). The objective of this study was to assess the 10-year probability of MOF and HF among a selected sample of Palestinian people.

Methods: A sample of 100 subjects was studied. Dual energy X-ray absorpitometry was performed to measure bone mineral density (BMD) which was then inserted into FRAX Palestine online WHO tool to calculate the 10-year probability of MOF and HF.

Results: The median age of participants was 61.5 years and the majority (79\%) were females. The median (interquartile range) of femoral hip BMD was $0.82(0.76-0.92) \mathrm{g} / \mathrm{cm}^{2}$. The mean vertebral and hip T scores were $-1.41 \pm 0.13$ SDs and $-0.91 \pm 0.10$ SDs respectively. About one fifth of the sample (21\%) had vertebral osteoporosis and 5\% had hip osteoporosis. The median (interquartile range) 10-year probability of MOF and HF based on BMD were 3.7 (2.43-6.18)\%, and 0.30 (0.10-0.68)\% respectively.

Conclusion: Osteoporosis is common among Palestinian people above 50 years old. Bone fracture prevention strategies and research should be a priority in Palestine. Using FRAX might be a helpful screening tool in primary healthcare centres in Palestine.
\end{abstract}

Keywords: FRAX, Osteoporosis, Palestine

\section{Background}

Osteoporosis is a progressive silent disease affecting bone mass and structure, leading to increased susceptibility to fractures [1,2]. The most common sites for osteoporotic fractures are the spine, hip, and wrist. Hip fractures (HP) are particularly devastating [3-5]. The World Health Organization (WHO) recently designed a tool to estimate the 10-year probability of HF and major osteoporotic fracture (MOF). This tool is called Fracture Risk Assessment Tool (FRAX) [6]. The tool, FRAX, is based on 11 risk factors plus the hip bone mineral density (BMD) if available. Each of the 11 factors used in FRAX tool provides some degree of independent information about fracture risk. These factors include age, sex, weight, height, a prior

\footnotetext{
* Correspondence: waleedsweileh@yahoo.com

2Division of Pharmacology/ Toxicology, College of Medicine and Health

Sciences, An-Najah National University, Nablus, Palestine

Full list of author information is available at the end of the article
}

fragility fracture, parental history of HF, current tobacco smoking, long-term use of glucocorticoids, rheumatoid arthritis, other causes of secondary osteoporosis and daily alcohol consumption. Since osteoporosis is a multifactorial disease, combination of risk factors with BMD produces the most effective risk assessment for MOF as opposed to assessment of any risk factor alone [7].

FRAX is intended for use in postmenopausal women and men over the age of 40 who have not taken osteoporosis medications. The tool is available online at (http://www. shef.ac.uk/FRAX/tool.aspx?country=52). Normal BMD or bone mineral content (BMC) is defined by the $\mathrm{WHO}$ as BMD or BMC score between \pm 1 standard deviations (SDs) from the young adult mean, as measured by central (hip or spine) dual energy $x$-ray absorpitometry (DEXA) scan [8]. Osteopenia is clinically defined as a BMD score between -1 and -2.5 SDs and osteoporosis as a BMD score 2.5 SDs or more below the young adult mean. The

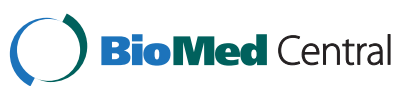

(c) 2013 Aker et al.; licensee BioMed Central Ltd. This is an open access article distributed under the terms of the Creative Commons Attribution License (http://creativecommons.org/licenses/by/2.0), which permits unrestricted use, distribution, and reproduction in any medium, provided the original work is properly cited. 
National Osteoporosis Foundation (NOF) recently developed guidelines based on FRAX and currently recommends starting treatment in individuals with any one of the following criteria: (1) history of hip or vertebral fracture, (2) T-score $\leq-2.5$ at femoral neck or spine, (3) $\mathrm{T}$-score between -1.0 and -2.5 and 10 -year probability $\geq$ $3 \%$ for hip fractures and $\geq 20 \%$ for MOF [9].

Palestine, or called the occupied Palestinian territories is located in the Middle East area. According to the latest report published by the Palestinian ministry of health (http://www.moh.ps/attach/441.pdf), Palestine has a total population of $(4,168,858)$; $(50.8 \%)$ are males and $(49.2 \%)$ are females. Population pyramid shows that $(40.8 \%)$ of the Palestinian population is under 15 years old, $14.7 \%$ is in the age group (0-4) years, and $2.9 \%$ is above 65 years. The natural increase of population was $2.9 \%$, and the crude birth rate was $(29.1 / 1,000)$ while fertility rate was 4.3 . The five main health providers of health services in Palestine are Ministry of health $(\mathrm{MOH})$, the United Nations Relief and Works Agency for Palestine Refugees in the Near East (UNRWA), Palestinian Non-Governmental Organizations (NGOs), Palestinian Military Medical Services (PMMS) and Private for profit organizations. The Palestinian $\mathrm{MOH}$ bears the heaviest burden, as it has the major responsibility. The NGOs sector operates more than 200 primary health care centres and general clinics in Gaza Strip and West Bank [10].

To the best of authors' knowledge, no studies have been carried out in Palestine or in other neighbouring Arab countries using FRAX $^{\circ}$ to estimate the 10-year probability bone fracture. Therefore, this study was carried out to measure the BMD and calculate the 10-year probability hip and MOF in a selected sample of Palestinian men and women older than 50 years.

\section{Methods}

\section{Study design and setting}

This study was a descriptive analytical study carried out at Al-Rahmah center which is a nongovernmental charitable organization that provides medical services for the general public. It includes outpatient specialist clinics, pharmacy, radiology and laboratory departments. It has a relatively high workload and it is the only center that provides DEXA in Nablus district, Palestine.

\section{Sampling method and ethical consideration}

Data collection process took place during April - June, 2012. One of the investigators visited Al-Rahmah center daily and stayed there from 9 am to $1 \mathrm{pm}$ to recruit participants. Potential candidates were approached and were invited to participate. Males or females above 50 years who did not have osteoporosis and were not using osteoporotic medication, except for calcium and vitamin D, were included in the study. Those having recent osteoporotic fractures were excluded.

Ethical approval was obtained from Institutional Review Board (IRB) at An-Najah National University. In addition, approval from Al-Rahmah clinic administration, and consent forms from participants were also obtained. Participants were assured privacy and confidentiality of data.

\section{Data collection tool}

The questionnaire used consisted of 1) socio-demographic information including sex, age, educational level, and marital status, 2) anthropometric measures including height, weight, and BMD, 3) medication and medical history of the participants and 4) dichotomous risk factors of FRAX tool.

Bone mass density was obtained by performing DEXA using Hologic DEXA machine at Al-Rahmah clinic radiology department. The hologic DEXA machine was set for white Mediterranean as reference value. Further classification was made based on the WHO classification for osteoporosis (BMD value is $-2.5 \mathrm{SD}$ or more below the mean for young adult mean) and osteopenia (BMD value between $-2.5 \mathrm{SD}$ and $-1 \mathrm{SD}$ ) to classify the subjects according to vertebral and hip osteoporosis. Weight and height were also recorded. Height was measured also by tape measure. When using FRAX/ Palestine tool, the DEXA result was entered as BMD measurement. The online FRAX tool calculates the 10-year probability of both $\mathrm{HF}$ and MOF.

\section{Data analysis}

The independent variables included in this study were: age (above 50 years); sex; marital status (single, married, widowed, and divorced); parity and use of oral contraceptives (OCT) in females; weight $(\mathrm{kg})$ and height (meter) to calculate body mass index (BMI); level of education (illiterate, basic education ( $1^{\text {st }}$ to $10^{\text {th }}$ grade), high school education, and college); administered medications, and chronic illnesses. Other investigated variables such as history of previous fracture, history of parental fracture, alcohol consumption, tobacco smoking, history of glucocorticoids use, rheumatoid arthritis, other secondary causes of osteoporosis, and exercise were presented as dichotomous variable. Secondary osteoporosis is present if the patient has a disorder strongly associated with osteoporosis. These include type I (insulin dependent) diabetes, osteogenesis imperfecta in adults, untreated long-standing hyperthyroidism, hypogonadism or premature menopause ( $<45$ years), chronic malnutrition, mal-absorption or chronic liver disease. The outcome variable in this study was the 10 -year probability $\mathrm{HF}$ and MOF calculated by the WHO FRAX tool for Palestine. 
Statistical analysis was conducted using Statistical Package for Social Sciences (SPSS) version 16.0 for Windows. Normality was tested using Kolmgorov-Smirnov test. Descriptive analysis for continuous variables was performed with mean and SDs or median and (interquartile range). Frequencies and percentages were calculated for categorical variables. Correlation was used to test relationship between BMD and 10-year probability of HF or MOF. Mann-Whitney $U$ test was used to test association between groups for variables that were not normally distributed. Differences were considered significant if the P-value was less than 0.05 .

\section{Results}

\section{Demographic and clinical characteristics of the participants}

One hundred and twenty people were invited to participate in the study, 12 refused to participate while 8 did the interview but refused to do the DEXA test, giving a net total sample of 100 subjects (Figure 1). Demographic and clinical characteristics of the participants are shown in Table 1. Age showed positive skewness with a median age (interquartile range) of 61.5 (55-67)

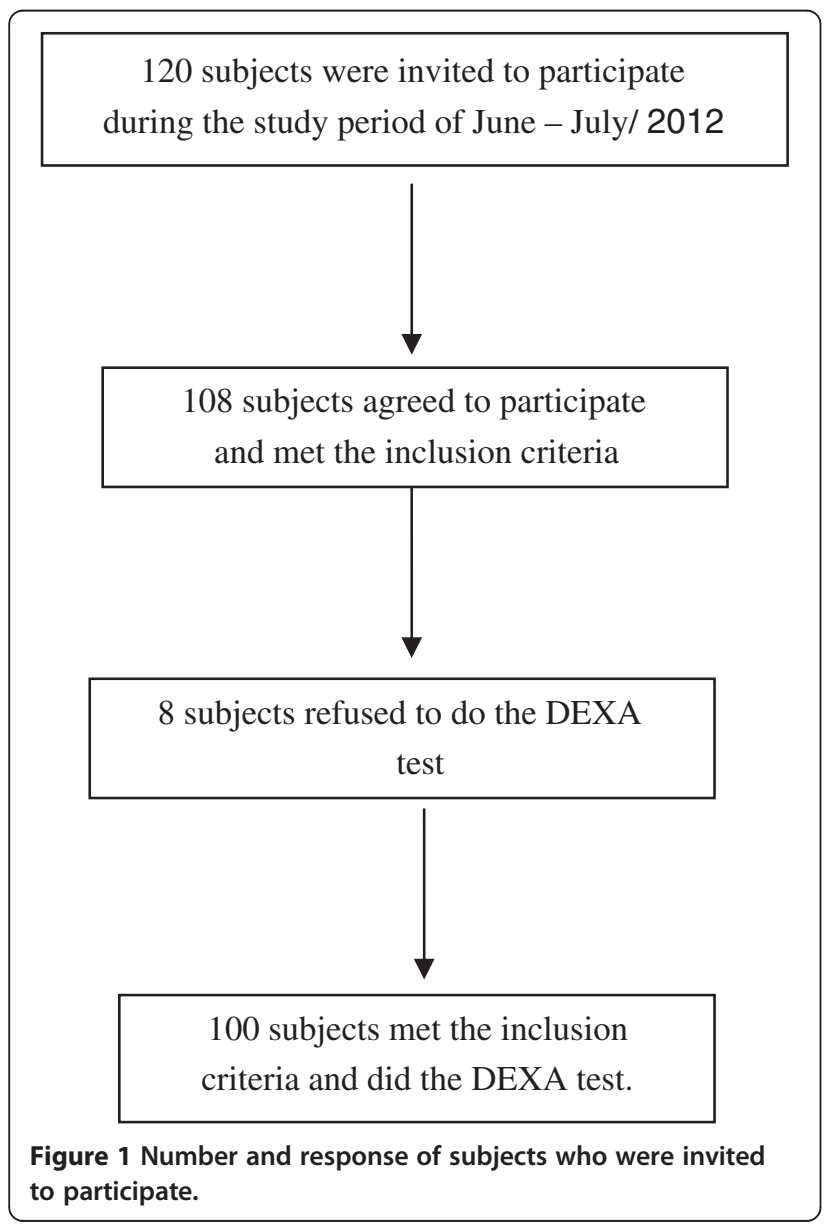

years. The majority (79\%) of participants were females. The mean \pm SD of BMI of the study sample was $32.20 \pm$ 4.69; for males was $28.92 \pm 4.91$, and for females was $33.07 \pm 4.26$. Nineteen percent of the participants were current tobacco users and 38\% exercised routinely at least 30 minutes a day three times a week. More than half of female participants $(53.16 \%)$ reported using oral contraceptives in the past. Twenty two percent of the participants had used oral corticosteroids. Twenty-two percent suffered from previous fracture and 15\% had at least one parent with previous HF.

\section{Dual energy X-ray}

The results of BMD had a median (interquartile range) of $0.82(0.76-0.92)$. The mean vertebral T score was $-1.41 \pm$ 0.13 SDs and the mean hip T score was - 0.91 \pm 0.095 SDs. Based on the WHO criteria, 21\% of the participants had vertebral osteoporosis, $29 \%$ had vertebral osteopenia and $50 \%$ were normal. Based on hip $\mathrm{T}$ scores, $5 \%$ had hip osteoporosis, $23 \%$ had hip osteopenia, and $72 \%$ were normal. Taken altogether, $23 \%$ had osteoporosis whether hip or vertebral (Table 2).

\section{Fracture risk assessment tool}

Using FRAX calculator with BMD data, the median 10year (interquartile range) probability for MOF was 3.7\% $(2.43-6.18)$ and that for HF was $0.3 \%(0.10-0.68)$. Two participants were at high risk of MOF $(\geq 20 \%)$ and 4 were at high risk of HF $(\geq 3 \%)$. Based on the NOF guideline, at least 24 participants needed immediate treatment. Table 3 shows data extracted from FRAX calculator. BMD was significantly and negatively correlated with both 10-year probability of MOF ( $\mathrm{p}<0.001, \mathrm{r}=-0.609)$ and HF ( $<<0.001, r=-0.845)$.

The median 10-year probability of MOF calculated based on BMD was significantly $(\mathrm{p}<0.05)$ associated with age > 65 years, female gender, patients who have more than 6 children, low educational level, history of previous fracture, history of parents' HF, history of no OCT use among females, history of oral corticosteroid use, secondary osteoporosis, and presence of rheumatoid arthritis but not with marital status, smoking, BMI, performing exercise, diabetes mellitus, and presence of cardiovasular diseases (CVD) or gastrointestinal tract (GIT) diseases.

The median 10-year probability of HF calculated based on BMD was significantly ( $p<0.05$ ) associated with age $>65$ years, patients who have high number of children (more than 6 children), low educational level, previous HF, secondary osteoporosis, use of corticosteroids, secondary osteoporosis, presence of GIT diseases and rheumatoid arthritis but not with gender, marital status, current tobacco smoking, BMI, exercising, previous history of parents' hip fractures, history of OTC use, and history of CVD. 
Table 1 Demographic and clinical characteristics of the participants

Variable name Statistics Mean \pm SD or Median

\begin{tabular}{lc} 
& (interquartile range) or N (\%) \\
\hline Age (years) & $61.5(55-67)$ \\
$50<$ Age $\leq 65$ & $72(72 \%)$ \\
$65<$ Age $\leq 90$ & $28(28 \%)$ \\
Gender & \\
Male & $21(21 \%)$ \\
Female & $79(79 \%)$
\end{tabular}

Marital status

Married

Others (single, widowed, or divorced)

$91(91 \%)$

$9(9 \%)$

Parity (for females)

Nulliparity

$8(10.13 \%)$

Have $\leq 6$ children

Have $>6$ children

$29(37.05 \%)$

$42(53.16 \%)$

\section{Education}

Illiterate

School educated

$18(18 \%)$

$58(58 \%)$

Achieved university degree

$24(24 \%)$

\section{Current tobacco use}

Yes

No

Body mass index

For males

For females

\section{Exercise}

Yes

No

Previous fracture

Yes

No

Previous parents' hip fracture

Yes

No

History of OCT use among females$$
\text { Yes }
$$

No

History of oral corticosteroid use

$$
\text { Yes }
$$

No

Secondary osteoporosis

Yes

No
Table 1 Demographic and clinical characteristics of the participants (Continued)

\begin{tabular}{ll}
\hline Diabetes mellitus & $29(29 \%)$ \\
Yes & $71(71 \%)$ \\
No & \\
Cardiovascular diseases & $60(60 \%)$ \\
Yes & $40(40 \%)$ \\
No & \\
Gastrointestinal tract disorders & $32(32 \%)$ \\
Yes & $68(68 \%)$ \\
No & \\
Rheumatoid arthritis & $25(25 \%)$ \\
Yes & $75(75 \%)$ \\
No & \\
\hline Abbreviations: SD standard difference, OCT oral contraceptives.
\end{tabular}

\section{Discussion}

The problem of osteoporosis will soon be of greater importance in developing countries due to the increase in life expectancy [11]. In the Middle East, the burden of this disease is expected to increase taking into account the steady growth of the ageing population. A study in Iran indicated that 2 million people are at risk of fracture and the cost of HF is between $6-8$ million United Sates dollars (USD) [12]. The prevalence of osteoporosis in post-menopausal Iranian women was reported to be 6 percent which is remarkably low compared to other countries. A recent survey conducted in Lebanon to determine risk factors for osteoporosis in the Lebanese female population found that back pain, low physical activity, family history of osteoporosis or HF, loss of height, early menopause, heavy smoking ( $>20$ cigarettes per day), thin and small build, history of rheumatoid or thyroid disease, previous administration of corticosteroids and chronic alcohol consumption were associated with increased MOF [13]. In Saudi Arabia, the prevalence of osteoporosis was studied in a group of randomly selected males and females aged 20-79 years; the prevalence in women was $28.2 \%$ [14]. In a study carried out in Qatar on healthy females aged 20 to 70, risk factors for osteoporosis were similar to those known to influence BMD in other populations; female sex, age, early menopause, and smoking [15]. In Palestine, a study conducted by Abd-Alhameed et al. (2010) on the prevalence and awareness to osteoporosis among randomly selected postmenopausal women found that osteoporosis at lumbar spine, neck and total hip was $24 \%, 14 \%$ and $29.7 \%$ respectively [16]. The authors of the Palestinian study concluded that $\mathrm{BMD}$ values declined $0.32-0.53 \%$ per year in relation to the number of years after menopause.

Several studies in Europe and Asia were carried out to assess the 10-year risk probability for bone fracture using 
Table 2 Results obtained from Dual Energy X-rays (DEXA)

\begin{tabular}{lc}
\hline Variable name & $\begin{array}{c}\text { Statistics Mean } \pm \text { SD or Median } \\
\text { (interquartile range), N (\%) }\end{array}$ \\
\hline Bone mineral density (hip) & $0.82(0.76-0.92) \mathrm{gl \textrm {cm } ^ { 2 }}$ \\
Vertebral T score & $-1.41 \pm 0.13$ \\
Hip T score & $-0.91 \pm 0.095$ \\
Vertebral osteoporosis & \\
Classification & $50(50 \%)$ \\
$\quad$ Normal & $29(29 \%)$ \\
Vertebral osteopenia & $21(21 \%)$ \\
Vertebral osteoporosis & \\
Hip osteoporosis classification & \\
Normal & $72(72 \%)$ \\
Hip osteopenia & $23(23 \%)$ \\
Hip osteoporosis & $5(5 \%)$ \\
\hline
\end{tabular}

Abbreviations: $S D$ standard difference.

FRAX but none were carried out in Arab world. A study in Bulgaria among women $>50$ years found that the mean 10-year absolute fracture risk was $13.4 \pm 9.2 \%$ (major fractures) and $2.8 \pm 5.2 \%$ (HP) [17]. A study in Taiwan found that the mean 10-year probabilities of MOF or HF were $13.8 \%$ (95\% confidence interval $(\mathrm{CI})=10.7 \%-16.9 \%)$ and $2.2 \%$ (95\% CI $=0.8 \%-3.5 \%$ ), respectively [18]. A study in Poland among 2012 post-menopausal women found that the mean 10-year probability of MOF or HF was $22.2 \pm$ $12.1 \%$ [19]. It is evident that the values obtained in our study were lower than that reported in other international studies. This difference could be attributed to geographical, cultural and nutritional habits in different parts of the world.

Osteoporosis is a major public health problem because of the fractures that could occur. Unfortunately, osteoporosis receives low attention in the primary health care programs in most underdeveloped countries where most women are largely unaware of the serious complications associated with osteoporosis [20]. Evidently, minimizing the risk of acquiring the disease begins by modification of individuals' life style to combat related risk factors and identification of patients at high risk to reduce future fractures. Many risk factors, some are modifiable and others non-modifiable are associated with osteoporosis. The major non-modifiable risk factors include advanced age, a personal history of fractures as an adult, and a history of fracture in a first degree relative [21,22]. Major modifiable risk factors include a low BMD, chronic oral corticosteroid use (more than 3 months of use), history of recurrent falls, and a low body weight (less than $58 \mathrm{~kg}$ ) [21-24]. Minor risk factors for MOF include, but are not limited to, inadequate nutritional supplementation of vitamin D and calcium, impaired eyesight despite correction, high alcohol and tobacco consumption, and immobilization [7,25,26].

Results of our study showed a good agreement with published studies regarding risk factors that are significantly associated with risk of fractures. However our results showed no significant association between the risk of fractures and BMI or regular exercise. In our study, the 10-year probability of MOF was significantly associated with higher age, female gender and multi parity. Our results are consistent with results published in literature where similar significant association between risk of osteoporosis and such variables was found [15,21]. Previous fracture, presence of secondary osteoporosis, rheumatoid arthritis, and administration of corticosteroid were also significantly associated with 10 -year probability of HF and MOF. Similar results were found in literature $[21,23,24]$. Smoking, exercising, and having a history of cardiovascular diseases were not significantly associated with 10 -year probability of MOF. This may be due to the small sample size which made it difficult to obtain statistical difference. Gastrointestinal diseases and diabetes mellitus were significantly associated with 10 year probability of HF. This may be due to their contribution to occurrence of secondary osteoporosis in this region, increasing the rates of HF.

Our study has few limitations. First the sample was limited to one district. It would be better if we could have sample from the whole west bank, but high cost of the DEXA was one of the barriers. Furthermore, the sampling was carried out at specific times, dates and on people attending a healthcare clinic. This might suggest that most of those participants were not healthy adults and this might affect the interpretation of our results and might limit the generalization of our results to the entire Palestinian population. In Palestine, recruitment of participants for such study is a very difficult task given the cultural barriers as well the nature of the test which requires certain procedures that might not be acceptable for some people. Second, the majority of the sample was females and obese people. Obesity is common among Palestinians particularly women [27]. This might be due to decreased physical activity and greater than necessary food consumption. In addition, leisuretime physical activity is not a common concept in the Palestinian context, especially for rural women, where lack of sex-segregated facilities and cultural norms are prohibitive factors. Women in urban areas face similar cultural restrictions [27]. The prevalence of obesity among participants might have increased the 10 -year probability estimation of bone fractures. Third, participants might have made errors related to recalling certain events or understanding certain questions. For example, most participants were not able to report accurately the presence of rheumatoid arthritis. Participants reported a 
Table 3 Association and correlation between 10-year probability of MOF and HF with demographic and clinical variables of the participants

\begin{tabular}{lll}
\hline Variable name & $\begin{array}{l}\text { Median (interquartile } \\
\text { range) 10-y prob. of }\end{array}$ & $\begin{array}{l}\text { Median (interquartile } \\
\text { range) 10-y prob. of } \\
\text { MOF; }(P \text { value })\end{array}$ \\
\hline
\end{tabular}

\section{Age category}

$50<$ Age $\leq 65$

$90 \geq$ Age $>65$

$$
\begin{array}{ll}
3.2 \%(2.20-6.08) & 0.2 \%(0.00-0.48) \\
4.9 \%(3.65-6.50) & 0.5 \%(0.4-0.98) \\
P=0.008^{\mathrm{a}} & P<0.001^{\mathrm{a}}
\end{array}
$$

\section{Gender}

Male

Female

$$
\begin{array}{ll}
3 \%(1.65-4.65) & 0.2 \%(0.00-0.45) \\
3.8 \%(2.70-6.5) & 0.4 \%(0.10-0.7) \\
P=0.024^{a} & P=0.087^{a}
\end{array}
$$

Marital status

Married

Others

$$
\begin{array}{ll}
3.5 \%(2.3-6.2) & 0.3 \%(0.1-0.6) \\
4.5 \%(3.2-5.55) & 0.6 \%(0.25-0.95) \\
P=0.47^{\mathrm{a}} & P=0.088^{\mathrm{a}}
\end{array}
$$

Parity

Null parity

Have $\leq 6$ children

$3.8 \%(2.58-4.4)$

$3 \%(2.30-5.3)$

Have $>6$ children

$$
5.3 \%(2.95-7.5)
$$$$
P=0.003^{b}
$$

\section{Education level}

Illiterate

$5.4 \%(3.78-7.35)$

School educated

Achieved university degree

\section{Current tobacco use}

Yes

No

BMI

Exercise

Yes

No

Previous fracture

Yes

No

Previous parents hip fracture

Yes

Table 3 Association and correlation between 10-year probability of MOF and HF with demographic and clinical variables of the participants (Continued)

History of OCT use

$\begin{array}{lll}\text { Yes } & 3.4 \%(2.45-5.33) & 0.3 \%(0.10-0.63) \\ \text { No } & 3.9 \%(2.9-7.2) & 0.4 \%(0.15-0.8) \\ & P=0.031^{a} & P=0.115^{\mathrm{a}}\end{array}$

History of corticosteroid use

$\begin{array}{lll}\text { Yes } & 6.7 \%(5.2-10.7) & 0.55 \%(0.2-1.03) \\ \text { No } & 3.05 \%(2.2-4.83) & 0.3 \%(0.1-0.5) \\ & P<0.001^{a} & P=0.031^{a}\end{array}$

Secondary

osteoporosis

$\begin{array}{lll}\text { Yes } & 5.4 \%(3.9-7.2) & 0.5 \%(0.3-1.2) \\ \text { No } & 3.4 \%(2.3-5.65) & 0.3 \%(0.1-0.6) \\ & P=0.013^{\mathrm{a}} & P=0.034^{\mathrm{a}}\end{array}$

Diabetes mellitus

$\begin{array}{lll}\text { Yes } & 4.9 \%(2.75-6.5) & 0.4(0.2-0.95) \\ \text { No } & 3.4 \%(2.30-5.5) & 0.3(0.1-0.5) \\ & P=0.12^{\mathrm{a}} & P=0.024^{\mathrm{a}}\end{array}$

Cardiovascular

diseases

$\begin{array}{lll}\text { Yes } & 3.9 \%(2.5-6.18) & 0.4 \%(0.1-0.7) \\ \text { No } & 3.3 \%(2.3-6.05) & 0.3 \%(0.1-0.6) \\ & P=0.418^{\mathrm{a}} & P=0.665^{\mathrm{a}}\end{array}$

Gastrointestinal tract

$\begin{array}{lll}\text { Disorders } & 4.9 \%(2.9-6.68) & 0.5 \%(0.13-0.95) \\ \text { Yes } & 3.35(2.3-5.93) & 0.25 \%(0.1-0.5) \\ \text { No } & P=0.09^{\mathrm{a}} & P=0.031^{\mathrm{a}}\end{array}$

Rheumatoid arthritis

$\begin{array}{lll}\text { Yes } & 5.3 \%(3.65-7.5) & 0.6 \%(0.4-1.1) \\ \text { No } & 3.3 \%(2.30-5.6) & 0.2 \%(0.1-0.5) \\ & P=0.002^{\mathrm{a}} & P=0.003^{\mathrm{a}}\end{array}$

Abbreviations: $S D$ standard difference, Q1-Q3 quartile 1, quartile 3, OCT oral contraceptives, MOF major osteoporotic fracture, $H F$ hip fracture, $B M I$ body mass index.

${ }^{\mathrm{a} S}$ Statistical significance of differences estimated with the Mann-Whitney U test.

${ }^{\mathrm{b}}$ Statistical significance of differences estimated with the Kruskal-Wallis test. 'Statistical significance of differences estimated with the Spearman's correlation coefficient.

history of joint pain which might be rheumatoid arthritis or osteoarithritis. However, we analyzed information related to history or current joint pain as if it is rheumatoid arthritis.

\section{Conclusions}

As a conclusion, our study indicated that osteoporosis is common among the study sample where one fifth of the participants had vertebral osteoporosis and 5\% had hip 
osteoporosis. The median 10-year probability of MOF was higher than that of HF and both were within reported range of published results. There is an urgent need of a comprehensive national program to screen for osteoporosis in Palestine. More care and attention should be targeted toward elderly and especially postmenopausal female with respect to preventive measures. More efforts on the level of MOH to adopt FRAX tool to be used as a screening tool for all individuals above 40 years before making DEXA as an approximate estimation of fracture risk is a priority. Increase awareness toward osteoporosis and prevention strategies among the general population and particularly in older population. Further research and studies regarding fracture rates, genetic component of osteoporosis, and evaluation of the applicability accuracy and feasibility of FRAX in Palestinian population are needed.

\begin{abstract}
Abbreviations
FRAXm: Fracture risk assessment (FRAX) tool; WHO: World health organization; MOF: Major osteoporotic fracture; $\mathrm{MOH}$ : Ministry of health; HF: Hip fracture; DEXA: Dual energy X-ray absorpitometry; BMD: Bone mineral density; IRB: Institutional review board; SPSS: Statistical package for social sciences; UK: United Kingdom; Q1-Q3: Lower - upper quartiles; SD: Standard deviation; OR: Odds ratio; Cl: Confidence interval;

RA: Rheumatoid arthritis; USA: United States of America;

CVD: Cerebrovascular disease; BMI: Body mass index; USD: The United States dollar; GIT: Gastrointestinal tract.
\end{abstract}

\section{Competing interests}

The authors declare that they have no competing interests.

\section{Authors' contributions}

All authors were involved in drafting the article and all authors approved the final version to be submitted for publication. All authors have added an intellectual significant value to the manuscript. MA was involved in subject recruitment and interview, data collection, data coding and entry, literature review, data analysis, data interpretation and manuscript editing. This was done in partial fulfillment of a master degree in Public Health program at An-Najah National University. AA was involved in concept, study design, manuscript writing and editing, and academic co-supervision for MA according to An-Najah university regulations. SZ and AS were involved in concept, study design, intellectual critique and data interpretation. SA was involved in concept, study design, critical editing and revision of the manuscript. WS was involved in the study conception and design, literature review, manuscript writing, manuscript submission, manuscript revision, head of the research group, and academic supervision for MA according to An-Najah university regulations. This manuscript is part of a project for master degree in the graduate program of public health. The project was initially and originally conceptualized and designed by the Clinical Pharmacology/ Toxicology Research Group at An-Najah National University (WS, AA, SZ, AS and SA). The project was then assigned to MA as a thesis project and was academically supervised by WS and AA in adherence to An-Najah University regulations with regard to academic supervision for graduate students. The project was successfully defended as a master thesis by MA at An-Najah University on Feb 2013. A copy of the full thesis is available at An-Najah National University library.

\section{Authors' information}

Professor Waleed M. Sweileh is the head of a research group (S.Z, S.A, A.S and A.A) which has published in the field of clinical pharmacology, toxicology, pharmacoepidemiology, social and community pharmacy, clinical pharmacy and medicine. The research group has also supervised many students in the fields of nursing, public health and pharmacy.

\section{Acknowledgement}

The authors would like to express many thanks and gratitude to the Dean of Graduate Studies at An-Najah University and the medical staff at Al-Rahma Clinic for their help and ethical approval to conduct this study.

\section{Author details}

${ }^{1}$ College of Graduate Studies, Public Health Program, An-Najah National University, Nablus, Palestine. ${ }^{2}$ Division of Pharmacology/ Toxicology, College of Medicine and Health Sciences, An-Najah National University, Nablus, Palestine. ${ }^{3}$ Division of Clinical Pharmacy, College of Medicine and Health Sciences, An-Najah National University, Nablus, Palestine.

Received: 24 May 2013 Accepted: 2 October 2013

Published: 5 October 2013

\section{References}

1. Siris ES, Boonen S, Mitchell PJ, Bilezikian J, Silverman S: What's in a name? what constitutes the clinical diagnosis of osteoporosis? Osteoporos Int 2012, 23(8):2093-2097.

2. Jiang E, Wang Z, Meng Q, Li S, Wang F, Shao G, Zhang L: Study on bone density at various skeletal sites for the diagnosis of primary osteoporosis. Cell Biochem Biophys 2012, 64(1):1-3.

3. Jin H, Lu Y: Cost-saving tree-structured survival analysis for hip fracture of study of osteoporotic fractures data. Med Decis Making 2010, 31(2):299-307.

4. Sahota O, Morgan N, Moran CG: The direct cost of acute hip fracture care in care home residents in the UK. Osteoporos Int 2012, 23(3):917-920.

5. Riggs BL: MLI: the worldwide problem of osteoporosis: insights afforded by epidemiology. Bone 1995, 17:505S-511S.

6. Kanis JOA, Johans Son H, Borgs Röm TF, ST Röm O, McCloskey E: FRAX ${ }^{\oplus} \mathrm{J}$ a new tool for assessing fracture risk: clinical applications and intervention thresholds. Medicographia 2010, 32:32-39.

7. Brown JP, Josse RG: 2002 clinical practice guidelines for the diagnosis and management of osteoporosis in Canada. CMAJ 2002, 167(10 Suppl):S1-S34.

8. Brown JP, Fortier M, Frame H, Lalonde A, Papaioannou A, Senikas V, Yuen CK: Canadian consensus conference on osteoporosis, 2006 update. J Obstet Gynaecol Can 2006, 28(2 Suppl 1):S95-S112.

9. Dawson-Hughes BTA, Melton $L$, et al: Implications of absolute fracture risk assessment for osteoporosis practice guidelines in the USA. Osteoporos Int 2008, 19(4):449-458.

10. Giacaman R, Khatib R, Shabaneh L, Ramlawi A, Sabri B, Sabatinelli G, Khawaja M, Laurance T: Health status and health services in the occupied Palestinian territory. Lancet 2009, 373(9666):837-849.

11. Cooper C, Campion G, Melton LJ 3rd: Hip fractures in the elderly: a worldwide projection. Osteoporos Int 1992, 2(6):285-289.

12. Larijani B, Resch H, Bonjour JP, Meybodi HRA, Tehrani MRM: Osteoporosis in Iran, overview and management. Iranian Journal of Public Health 2007, 36:1-13. Supplement.

13. Kamel HKHM, Tariq S, Perry HM, Morley JE: Failure to diagnose and treat osteoporosis in elderly patients hospitalized with hip fracture. Am J Med 2000, 109:326-328.

14. El-Dessouki N: Osteoporosis in postmenopausal Saudi women using X-ray bone densitometry. Saudi Med J 2003, 24:935-936.

15. Maalouf G, Gannage-Yared MH, Ezzedine J, Larijani B, Badawi S, Rached A, Zakroui L, Masri B, Azar E, Saba E, et al: Middle East and North Africa consensus on osteoporosis. J Musculoskelet Neuronal Interact 2007, 7(2):131-143.

16. Abd-Alhameed I, Saba E, Darwish HM: Prevalence and awareness of osteoporosis among postmenopausal Palestinian women. Arch Osteoporos 2004, 5(1-2):111-118.

17. Borissova AM, Rashkov R, Boyanov M, Shinkov A, Popivanov P, Temelkova N, Vlahov J, Gavrailova M: Femoral neck bone mineral density and 10-year absolute fracture risk in a national representative sample of Bulgarian women aged 50 years and older. Arch Osteoporos 2011, 6(1-2):189-195.

18. Li YM, Liu SH: Estimation of the 10-year Probability of Osteoporotic Fracture in Postmenopausal Taiwanese Women With FRAX. TzU Chi Medical Journal 2010, 22(1):29-35.

19. Pluskiewicz W, Adamczyk P, Franek E, Leszczynski P, Sewerynek E, Wichrowska H, Napiorkowska L, Kostyk T, Stuss M, Stepien-Klos W, et al: Tenyear probability of osteoporotic fracture in 2012 Polish women assessed by FRAX and nomogram. conformity between methods and their clinical utility. Bone 2010, 46(6):1661-1667. 
20. Dawson-Hughes B: A revised clinician's guide to the prevention and treatment of osteoporosis. Journal of Clinical Endocrinology \& Metabolism 2008, 93(7):2463-2465.

21. Trombetti AHF, Hoffmeyer P, Schurch M, Bonjour J, Rizzoli R: Survival and potential years of life lost after hip fracture in men and age-matched women. Osteoporos Int 2002, 13(9):731-737.

22. Cummings SRNM, Browner WS, Stone K, Fox KM, Ensrud KE, et al: Risk factors for hip fracture in white women. N Engl J Med 1995, 332:767-773.

23. Van Staa TP LH, Abenhaim L, Zhang B, Cooper C: Oral corticosteroids and fracture risk: relationship to daily and cumulative doses. Rheumatology (Oxford) 2000, 39:1383-1389.

24. Marshall DJO, Wedel H: Meta-analysis of how well measures of bone mineral density predict occurrence of osteoporotic fractures. BMJ 1996, 312:1254-1259.

25. Ringe J: Osteoporosis in men. Medicographia 2010, 32:71-78,

26. Chrischilles EA, Butler CD, Davis CS, Wallace RB: A model of lifetime osteoporosis impact. Arch Intern Med 1991, 151(10):2026-2032

27. Abdul-Rahim HF, Holmboe-Ottesen G, Stene LC, Husseini A, Giacaman R, Jervell J, Bjertness E: Obesity in a rural and an urban Palestinian West Bank population. Int J Obes Relat Metab Disord 2003, 27(1):140-146.

doi:10.1186/1471-2474-14-284

Cite this article as: Aker et al: Estimation of 10 - year probability bone fracture in a selected sample of Palestinian people using fracture risk assessment tool. BMC Musculoskeletal Disorders 2013 14:284.

\section{Submit your next manuscript to BioMed Central and take full advantage of:}

- Convenient online submission

- Thorough peer review

- No space constraints or color figure charges

- Immediate publication on acceptance

- Inclusion in PubMed, CAS, Scopus and Google Scholar

- Research which is freely available for redistribution 